\title{
Performance Analysis of Dynamic Voltage Restorer for Voltage Sag and Swell Compensation in Distribution System
}

\author{
Dr. Han Su Yin \\ Professor \\ Department of Electrical Power Engineering, \\ Yangon Technological University \\ Yangon, Myanmar
}

\author{
Shwe Zan Aung \\ Project \& System Design Engineer \\ Omega Integration PTE Ltd \\ Singapore
}

\begin{abstract}
Nowadays, most of the electrical loads are concerned about the power quality. Power quality problems include voltage sags/swell, transient interrupts and harmonic distortions in sinusoidal waveforms. Modern industrial devices are mostly based on electronic devices such as programmable logic controllers and electronic drives. These electronic devices are very sensitive to disturbances and become less tolerant to power quality problems such as voltage sags, swells and harmonics. Voltage dips are considered to be one of the most severe disturbances to the industrial equipment. In this paper, voltage sag/swell study is carried out for Myaungtagar industrial zone where the steel mills are the main loads. Due to furnaces and large motor drives, the voltage sag/swell is the common problems in this system. To mitigate these voltage sag/swell problems, the Dynamic Voltage Restorer (DVR) is introduced for this system. Dynamic Voltage Restorer (DVR) is a series connected power electronics based device that can quickly mitigate the voltage sag in the system and restore the load voltage to the nominal value. In this paper, modeling and analysis of Dynamic Voltage Restorer (DVR) is presented which will use for voltage sag/swell compensation. Modeling and simulations are carried out with Matlab/Simulink.
\end{abstract}

Keywords: Voltage regulation, Voltage sag, Voltage swell, Dynamic Voltage Restorer, Hysteresis Control

\section{INTRODUCTION}

Power distribution systems should provide their customers with an uninterrupted power supply at smooth sinusoidal voltage at the contracted magnitude level and frequency. However, power distribution systems have numerous nonlinear loads which significantly affect the quality of power supplies. The waveform of the supply system may loss purity of sinusoidal due to the nonlinear loads. This ends up producing many power quality problems. Apart from nonlinear loads, some system events, both usual (e.g. capacitor switching, motor starting) and unusual (e.g. faults) could also suffer power quality problems. ${ }^{[1]}$

In modern distribution system, the substantial pollution and abnormal operating conditions can cause the number of voltage-based power quality (PQ) problems. These power quality problems at point of common coupling (PCC) occur due to the voltage drop in feeders and transformers, faults, use of unbalanced lagging power factor consumer loads, various kinds of disturbances, and so on. Some of these voltagerelated power quality problems are surges, flickers, sags, swells, notches, fluctuations, voltage imbalance, waveform distortion, and so on. The active series compensators are extensively used to both inject the voltage of required magnitude and frequency and restore the voltage across the loads to protect the sensitive loads from these voltage quality problems. Solid-state synchronous series compensators (SSCs) and dynamic voltage restorers (DVRs) are known as compensators. ${ }^{[2]}$

The DVR is a series connected power electronics based device, which can protect the system against the bulk of these disturbances, i.e. voltage sags and swells related to remote system faults. A DVR can compensate for these voltage excursions, provided that the supply system does not get disconnected entirely through breaker trips. The control systems of a DVR for main considerations are including such as: sag detection, voltage reference generation and transient and steady-state control of the injected voltage. The typical power quality disturbances are voltage sags, voltage swells, interruptions, harmonics and transients. Among the disturbances, voltage sag is considered the most severe since the sensitive loads are very susceptible to temporary changes in the voltage. ${ }^{[3]}$

\section{VOLTAGE REGULATION AND SAG/ SWELL IN DISTRIBUTION SYSTEM}

Modern power systems operate at some standard voltages. The equipment working on these systems are therefore given input voltages at these standard values, within certain agreed tolerance limits. It is necessary to quantify the drop that takes place inside a transformer when certain load current, at any power factor, is drawn from its output leads. This drop is termed as the voltage regulation and is expressed as a ratio of the terminal voltage. ${ }^{[5]}$ For proper operation of the electrical loads, the voltage regulation should be within $\pm 10 \%$ of nominal voltages at distribution level.

$$
\text { Voltage Regulation }=\frac{\left|\mathrm{V}_{\mathrm{nl}}\right|-\left|\mathrm{v}_{\mathrm{fl}}\right|}{\left|\mathrm{V}_{\mathrm{nl}}\right|}
$$

\subsection{Voltage Sag:}

The voltage sag is a decrease to between 0.1 and $0.9 \mathrm{pu}$ in $\mathrm{rms}$ voltage or current at the power frequency for durations from 0.5 cycle to $1 \mathrm{~min}^{[5]}$. The voltage signal with sag waveform is shown in Figure 1. Sometime, voltage sag last for long duration such prolonged low voltage profile referred as 
'under-voltage'. Voltage sag is further divided in three categories: instantaneous, momentary and temporary sags respectively. ${ }^{\left[{ }^{[6]}\right.}$ In distribution system, voltage sag conditions can be occurred due to occurrence of faults in power system, excessive loads, starting of large induction motors, the electric furnaces and electrical faults. Voltage sag in power system network results in failure of relays and contactor, dim light and fluctuating power.

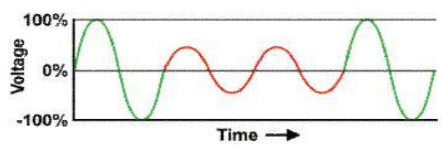

Figure 1. Voltage Signal with Sag Waveform

\subsection{Voltage Swell:}

Voltage swell is defined as an increase between 1.1 and $1.8 \mathrm{pu}$ in rms voltage or current at the power frequency for durations from 0.5 cycle to $1 \mathrm{~min} .{ }^{[5]}$ The voltage signal with swell is shown in Figure 2. Likewise voltage sag, prolonged high voltage profile is referred as 'over-voltage'. Voltage swell is subdivided as: instantaneous swell, momentary swell, temporary swell. ${ }^{[6]}$ In distribution system, voltage swell conditions can be occurred due to capacitor bank switching, turning on of lightly loaded lines and sudden turning off of large loads as well as Single line to ground fault (SLG) which can result in voltage rise in un-faulted phases and loose connection of neutral wire. Voltage swells results in breakdown of insulation, overheating of electrical equipment and damage to electronic equipment.

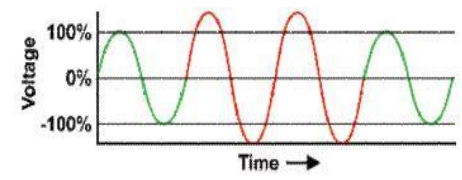

Figure 2. Voltage Signal with Swell Waveform

\section{MITIGATION TECHNIQUES FOR VOLTAGE SAG/SWELL}

Power devices have proven to be an attractive solution to the voltage sag/swell problem. Different solutions for improving the performance of the power system, as well as the immunity of the equipment, are described. Finally, mitigation devices to be installed at the system-load interface for power quality enhancement are DVR (Dynamic Voltage Restorer), UPS (Uninterruptible Power Supply), D-STATCOM (Distribution Static Synchronous Compensator) and so on.

\subsection{Advantages of DVR}

DVR is cheaper than D-STATCOM and UPS. UPS requires a lot of maintenance which may be due to problems of battery leakage and replacement. D-STATCOM is more complex to control and maintain than DVR. DVR is smaller in size and is a better power effective device as compared to others link UPS, and D-STATCOM. Therefore, this paper emphasize on the DVR for voltage sag/swell compensation.

\section{CONSTRUCTION AND OPERATION OF DVR}

A DVR is a custom power device used at distribution level. The DVR is implemented using voltage source converter (VSC) with fast switching power semiconductor devices such as IGBT or IGCT. The voltage injected by VSC in series with distribution feeder is controlled by using Hysteresis control technique. The rapid switching capability provided by IGBT enables the use of more sophisticated control technique to provide dynamic compensation to sag and swell.

\subsection{Basic Structure:}

The DVR is a series connected power electronic device used to inject voltage of required magnitude and frequency. The basic structure of a DVR is shown in Figure 3. It contains the following components:

- Voltage Source Converter (VSC)

- DC storage unit

- Filter circuit

- Series Transformer

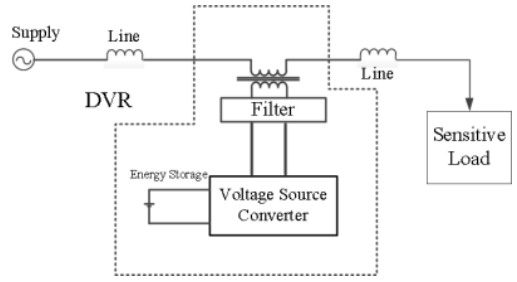

Figure 3. Schematic Diagram of Dynamic Voltage Restorer (DVR)

\subsubsection{Voltage Source Converter (VSC):}

A VSC is a power electronic system consists of a storage device and switching devices, which can generate a sinusoidal voltage at any required frequency, magnitude, and phase angle. In the DVR application, the VSC is used to temporarily replace the supply voltage or to generate the part of the supply voltage which is missing [7]. The VSC consists of solid state switches like IGBT's or GTO's used to convert the DC input to $\mathrm{AC}$. It is used to inject the $\mathrm{AC}$ voltage to compensate the decrease in the supply voltage. The switches of the VSC are operated based on the gate pulses supplied from the drive circuits via PWM or hysteresis controller.

\subsubsection{Storage Unit:}

The storage unit may consist of batteries, capacitors, flywheel, or super magnetic energy storage (SMES). For DVR with internal storage capacity, energy is taken from the faulted grid supply during the sag. Here, a rectifier is used to convert the AC voltage from the grid to DC voltage required by the voltage source converter. ${ }^{[4]}$

\subsubsection{Filter Circuit:}

A filter circuit consists of an inductor and capacitor. It is used to filter out the switching harmonic components from the injected voltage. An LC filter is connected at the output of the VSC to filter the harmonics that are present in the output voltage of VSC. Filter has a small rating, approximately $2 \%$ of the load MVA connected to delta-connected tertiary winding of the injection transformer. ${ }^{[1]}$

\subsubsection{Series Transformer:}

A series transformer is used to connect the DVR with the distribution feeder. In case of three phase system, three single phase transformers are used to connect the DVR with the power network. ${ }^{[4]}$

\subsection{The DVR Operation Modes}

The basic operation principle of DVR is measuring the missing voltage by using control unit and injecting the dynamically controlled missing voltage in series to the line and providing the load voltage unchanged during sag. The phase angle and amplitude of the injected voltage are variable during sag. This will allow the control of active and reactive power exchange between the DVR and the distribution system. Generally, the operation of the DVR can be 
categorized into three operation modes: protection mode, standby mode (during steady state) and injection mode (during sag).

\section{INDUSTRIAL DISTRIBUTION SYSTEM UNDER STUDY}

In this paper, the case study area is chosen at Myaungtagar industrial distribution zone. It has seventeen feeders. Eight feeders are connected with $230 \mathrm{kV} / 33 \mathrm{kV}$ 100MVA step-down transformer, five feeders are connected with $230 \mathrm{kV} / 33 \mathrm{kV}$, 60MVA step-down transformer, and four feeders are connected with $230 \mathrm{kV} / 33 \mathrm{kV}, 150 \mathrm{MVA}$ transformer respectively.

This paper is emphasized on 100MVA transformer side in which the power quality problem occurs due to industrial loads such as steel mill loads. The single line diagram of case study area is shown in Figure 4. The names of the feeders are Zone 1, Zone 2, Zone 3, Zone 4, Zone 5, Zone 5, Zone 6, Fertilizer 1, and Fertilizer 2 respectively.

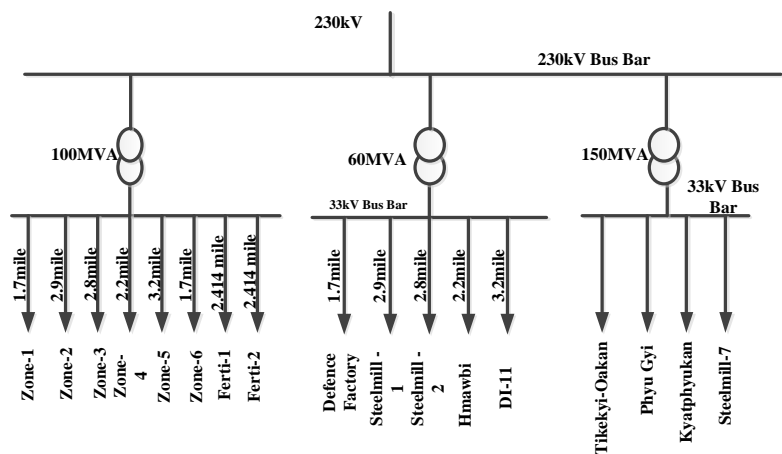

Figure 4. Single Lind Diagram of Case Study Area

\section{MODELING OF DVR}

Figure 5 shows the demand power of eight feeders for a typical day in the existing system of case study area. According to this load demand graph, power consumption of the system is rising during 8 am to $4 \mathrm{pm}$ in the peak hour of the day. Maximum load consumption is between 11 am to 1 pm as per the graph.

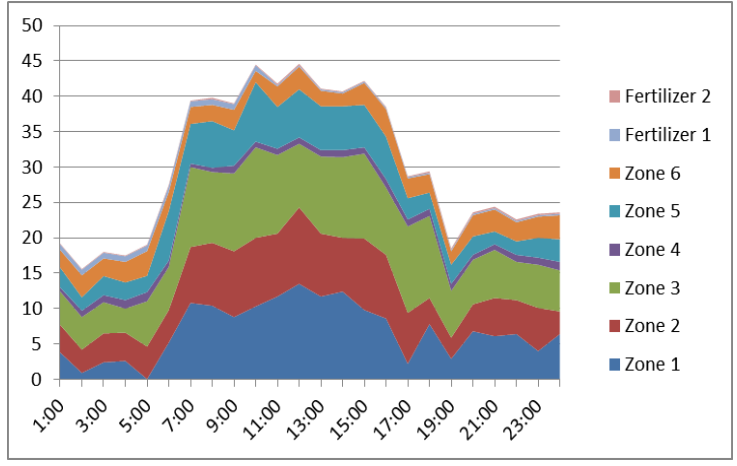

Figure 5. Demand Power of Eight Feeders for a Typical Day

Table 1 describes the parameter of the simulation model for the existing system of the case study area. This table includes the active power, reactive power and line length of each feeder for the case study area. Among the eight feeders, Zone 1 , Zone 2 and Zone 3 have the highest load demand. Fertilizer 1 and Fertilizer 2 have the minimum value of the active and reactive power. These data are collected from Myaungtagar
Industrial Distribution Substation base on the load consumption of May, 2018.

Table 1. Parameter of Simulation Model

\begin{tabular}{|c|c|c|c|}
\hline Feeders & $\begin{array}{c}\text { Line } \\
\text { Length } \\
\text { (km) }\end{array}$ & $\begin{array}{c}\text { Reactive powers } \\
\text { (MVAR) }\end{array}$ & $\begin{array}{c}\text { Active } \\
\text { powers } \\
\text { (MW) }\end{array}$ \\
\hline Zone 1 & 2.735885 & 3.65998 & 6.89708 \\
\hline Zone 2 & 4.6671 & 4.80004 & 6.36667 \\
\hline Zone 3 & 4.50616 & 4.874777 & 8.30833 \\
\hline Zone 4 & 3.540557 & 0.72029 & 0.93333 \\
\hline Zone 5 & 5.1499 & 3.33267 & 4.25833 \\
\hline Zone 6 & 2.73588 & 1.91355 & 2.75 \\
\hline Ferti 1 & 2.41402 & 0.2179 & 0.45 \\
\hline Ferti 2 & 2.41402 & 0.0605 & 0.1458 \\
\hline
\end{tabular}

Figure 6 describes the modeling of the existing system when fault occurs at the load side. The case study area of the industrial distribution system source voltage $230 \mathrm{kV}$ is connected with $230 \mathrm{kV} / 33 \mathrm{kV}$ step down transformer. The outgoing of the step down transformer distribute the voltage for the eight feeders.

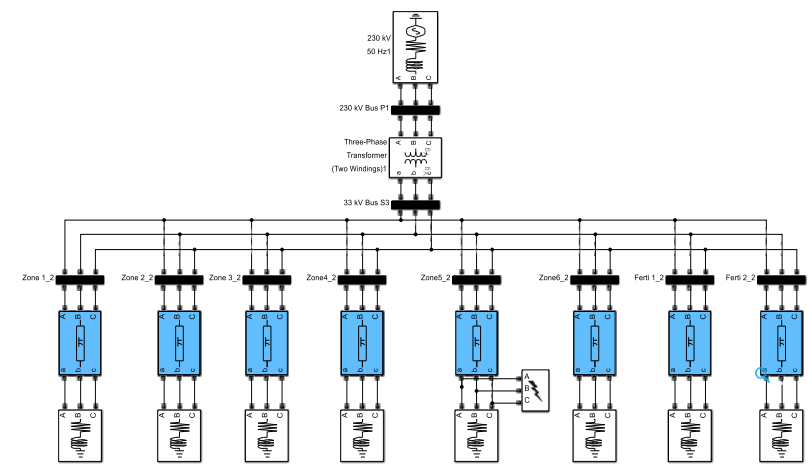

Figure 6. Existing System When Fault occurs at load side

\section{PERFORMANCE ANALYSIS FOR SAG/SWELL COMPENSATION}

In the performance analysis for the voltage sag/swell simulation of modeling the existing system, we will consider two options. For the voltage sag condition, the system have various fault conditions occurs at the load side and for the voltage swell condition, the capacitive load is connected to the system. For the voltage sag condition, the fault is applied at Zone 5 which is the longest line length and average load among the feeders of the system. Therefore, it has the most chance for the occurrence of fault. For the voltage swell condition, capacitive load, 50MVAR is attached at $33 \mathrm{kV}$ transformer side in parallel with the load feeder.

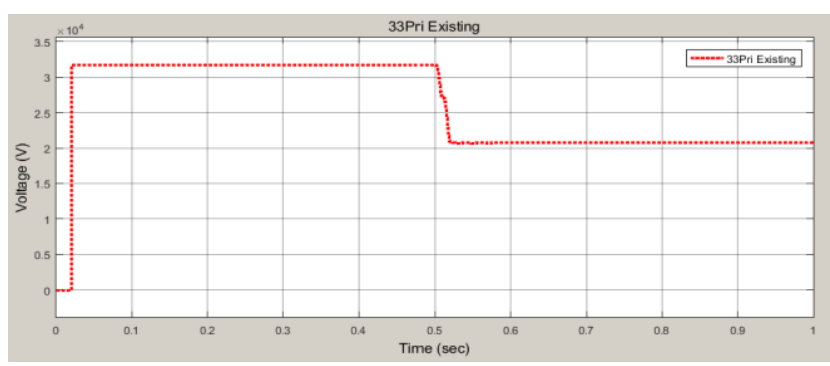

Figure 7. Voltage Profile of the System when Single Line to Ground Fault Occurs 
Figure 7, Figure 8, Figure 9 and Figure 10 show the voltage profile of the existing system when the system is suffer from the various fault conditions. The fault is occurred at $0.5 \mathrm{sec}$ and the system voltage decrease lower than $33 \mathrm{kV}$. The voltage sag magnitude are $18.11 \mathrm{kV}$ for three phase fault, $11.75 \mathrm{kV}$ for line to line fault, $12.225 \mathrm{kV}$ for single line to ground fault, and $14.918 \mathrm{kV}$ respectively.

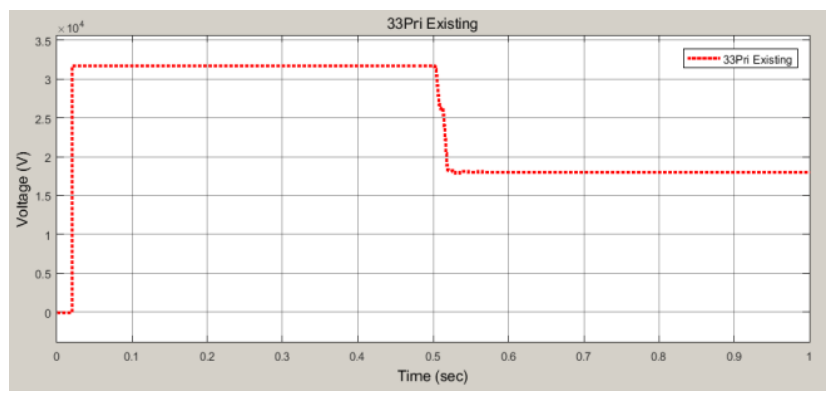

Figure 8. Voltage Profile of the System when Double Line to Ground Fault Occurs

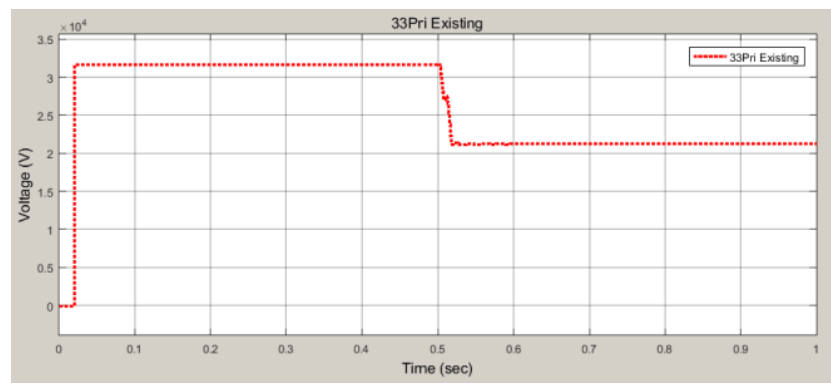

Figure 9. Voltage Profile of the System when Line to Line Fault occurs

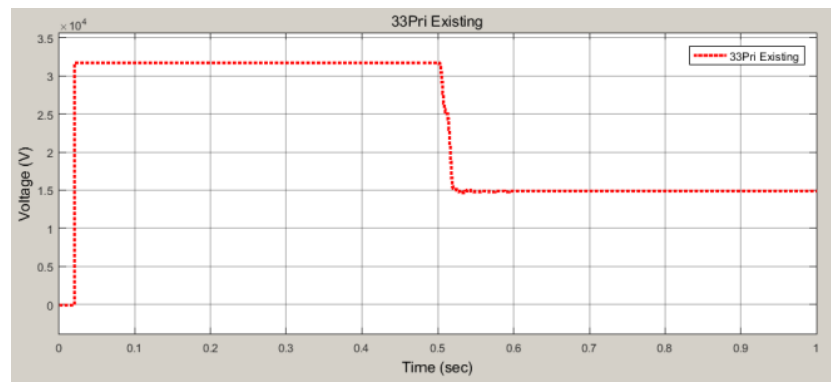

Figure10. Voltage Profile of the System when Three Phase Fault occurs

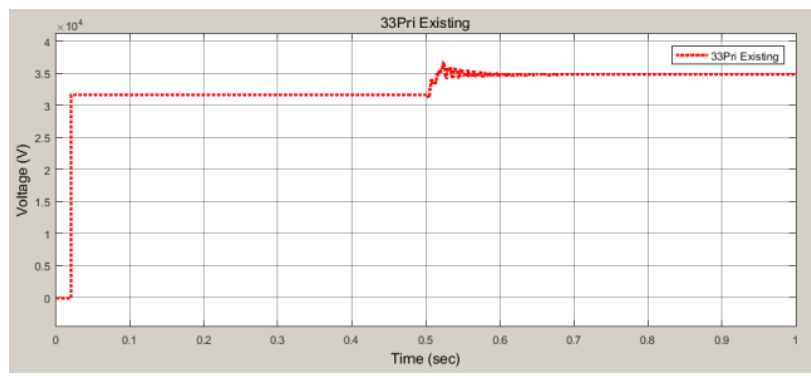

Figure 11. Voltage Profile of the System when the Capacitive Load is connected

Figure 11 shows the voltage profile of the system when the capacitive load is connected. When the capacitive load is connected at $0.5 \mathrm{sec}$, the system voltage is increased from $33 \mathrm{kV}$ to $34.83 \mathrm{kV}$.
Table 2. System Data of the DVR Model

\begin{tabular}{|l|l|}
\hline System Voltage & $33 \mathrm{kV}$ \\
\hline Series Transformer Turn Ratio & $1: 3$ \\
\hline DC Link Voltage & $44.567 \mathrm{kV}$ \\
\hline Filter Inductance & $94 \mathrm{mH}$ \\
\hline Total Active Power & $30.10954 \mathrm{MW}$ \\
\hline Total Reactive Power & $19.57971 \mathrm{MVAR}$ \\
\hline
\end{tabular}

To compensate for the voltage sag and swell condition, modeling of the DVR is constructed in the existing system. Table 2 shows the system data of the DVR model.

Figure 12 shows Existing System is connected with DVR when fault occurs at load side. DVR is connected in series with $33 \mathrm{kV}$ source side and $33 \mathrm{kV}$ load side of the system via three $25 \mathrm{MVA}, 33 \mathrm{kV} / 11 \mathrm{kV}$, single phase transformers. The secondary side of these single phase transformer are connected with voltage source converter (VSC). DC terminal of Voltage Source Converter (VSC) are connected with Battery. Figure 13 describe the modeling of Hysteresis controller.

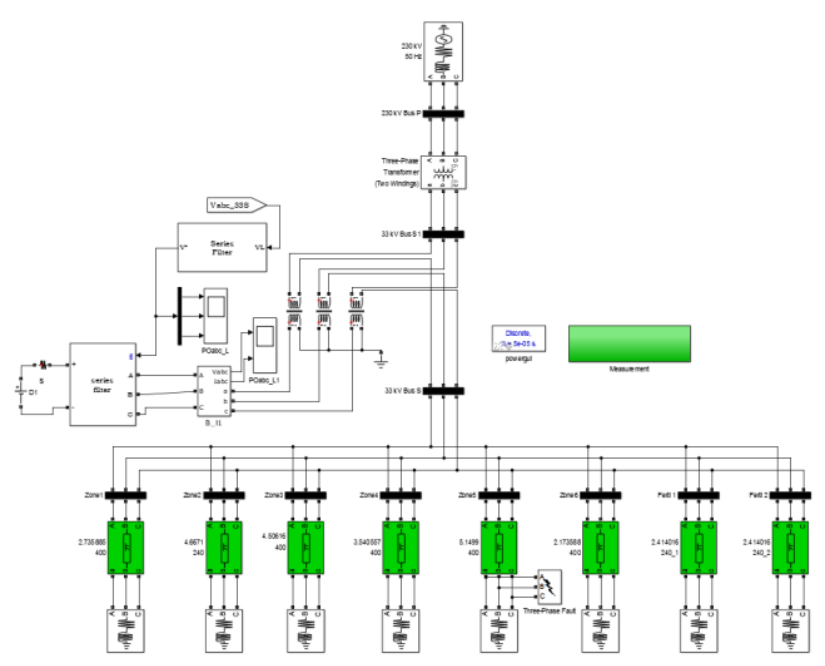

Figure 12. Existing System is connected with DVR when Fault occurs at Load Side

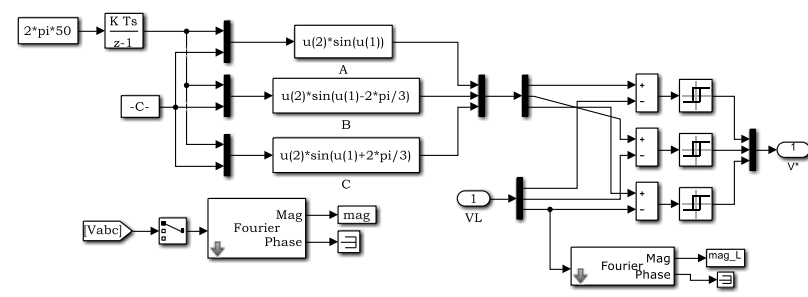

Figure 13. Modelling of Hysteresis Controller

A DVR can compensate the voltage drop or voltage swell across a load by injecting or absorption a voltage through a series transformer with the source voltage. Voltage Source Converter (VSC) is used with hysteresis control for this purpose. In this control, control signal is produced by using error signal which get from the comparing reference voltage and actual voltage with Hysteresis control .Voltage Source Converter (VSC) is operated by the controlled signal which is also get from the Hysteresis control. 


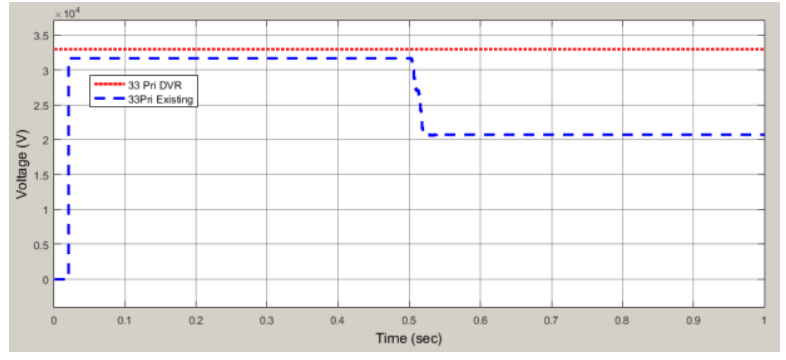

Figure 14. Voltage Profile of the System with and without DVR when Single Line to Ground Fault occurs

Figure 14, Figure 15, Figure 16, and Figure 17 show voltage profile with and without DVR when various fault conditions occurs in the existing system. Without DVR, the bus voltages are significantly reduced below the rated value. With DVR, the bus voltages are maintained at rated values. Thus DVR can restore the bus voltages under various fault conditions.

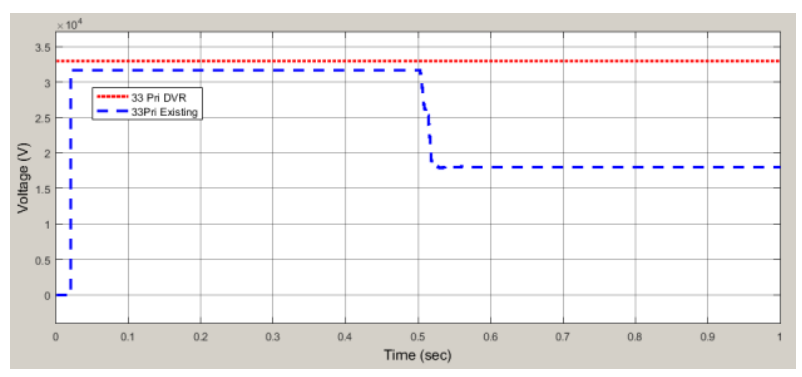

Figure 15. Voltage Profile of the System with and without DVR When Double Line to Ground Fault Occurs

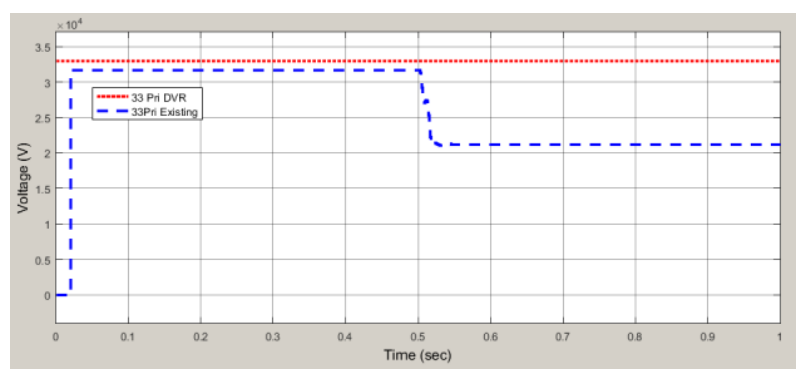

Figure 16. Voltage Profile of the System with and without DVR when Line to Line Fault Occurs

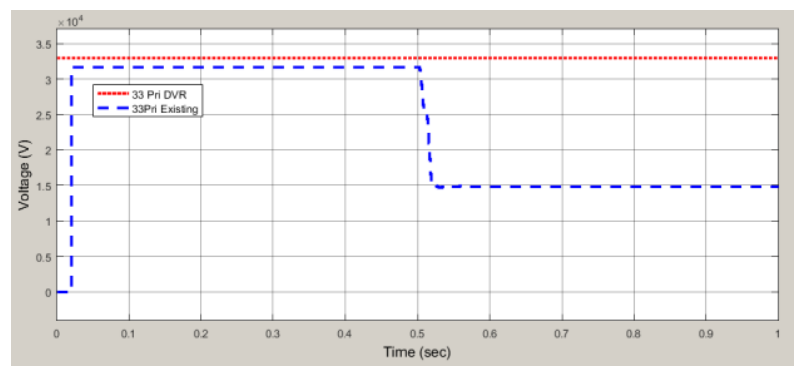

Figure 17. Voltage Profile of the System with and without DVR when Three Phase Fault occurs

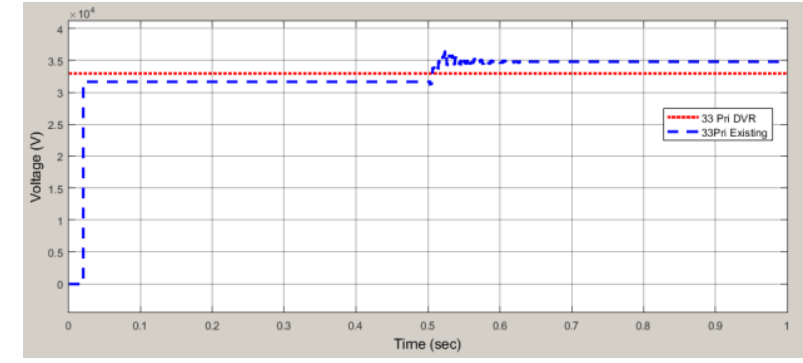

Figure 18. Voltage Profile of the System with and without DVR When Capacitive Load is connected

Figure 18 shows voltage profile with and without DVR when capacitive load is connected in the proposed system. Without DVR, the bus voltage is increased with the application of capacitive load. When DVR is contected with the existing system, the volatge profile is better than without DVR of the system. The simulation results with and without DVR in the existing system are tabulated in Table 3 .

Table 3.Simulation Results with and without DVR

\begin{tabular}{|l|c|c|}
\hline \multicolumn{1}{|c|}{ Fault Type } & $\begin{array}{c}\text { Existing } \\
\text { System } \\
\text { without DVR }\end{array}$ & $\begin{array}{c}\text { Existing } \\
\text { System with } \\
\text { DVR }\end{array}$ \\
\hline Three Phase Fault & $14.890266 \mathrm{kV}$ & $33.0022 \mathrm{kV}$ \\
\hline Line to Line Fault (A \&B) & $21.2485 \mathrm{kV}$ & $33.0017 \mathrm{kV}$ \\
\hline Single Line to Ground Fault & $20.77545 \mathrm{kV}$ & $33.00046 \mathrm{kV}$ \\
\hline DL-G Fault (A \&B) & $18.0823 \mathrm{kV}$ & $33.00179 \mathrm{kV}$ \\
\hline Capacitive Load Connected & $34.832 \mathrm{kV}$ & $32.9972 \mathrm{kV}$ \\
\hline
\end{tabular}

\section{CONCLUSION}

The modeling and simulation of a DVR for voltage sag/swell mitigation in industrial distribution system is presented in this paper. Myaungtagar Substation is chosen as case study area where the steel mills are the main loads and the voltage sag/swell is the main problems. Therefore, economical loss and degradation in power quality result due to these voltage deviations. In this paper, DVR is used as a voltage sag/swell mitigation device and use to protect the sensitive loads in the system. The simulation result shows that the voltage sag/swell in the system can be fully mitigated by using DVR. Therefore, the dynamic voltage restorer presented in this paper is efficient and reliable for mitigation of voltage sag/swell in the industrial distribution system.

\section{ACKNOWLEDGMENTS}

I would like to express my sincere appreciation to Myaungtagar Industrial Distribution Substation for the support on data collecting. I also would like to acknowledge special thanks to all of my teachers, my seniors and colleagues from Department of Electrical Power Engineering for their support and encouragement towards this paper.

\section{REFERENCES}

[1] S.Saravanan1, M. Solaimanigandan, T. Tharaneetharan, V. Varunraj, "Dynamic Voltage Restorer for Distribution System", International Journal of Engineering Research and Development e-ISSN: 2278-067X, p-ISSN: 2278800X, Volume 7, Issue 1 (May 2013), 14-24.

[2] Bhim Singh, Ambrish Chandra, Kamal Al-Haddad. 2015. Power Quality Problems And Mitigation Techniques, 
[3] Sanjay Haribhai Chaudhary, Mr. Gaurav gangil, "Mitigation of voltage sag/swell using Dynamic Voltage Restorer (DVR)", IOSR Journal of Electrical and Electronics Engineering (IOSR-JEEE) e-ISSN: 22781676,p-ISSN: 2320-3331, Volume 8, Issue 4 (Nov. Dec. 2013), 21-38.

[4] Sandeep Kumar N. 2012-2014, Power Quality Issues and its Mitigation Techniques,
[5] Roger C. Dugan, Mark F. Mc Granaghan, Surya Santoso, H. Wayne Beaty. 2004. Electrical Power System Quality,

[6] Dev Kumar Taram. 2015. Power Quality Improvement Using Dynamic Voltage Restorer (DVR).

[7] T.Devaraju1, V. C. Veera Reddy and M. Vijaya Kumar. "Performance of DVR under different voltage sag and swell conditions", ARPN Journal of Engineering and Applied Sciences, ISSN 1819-6608, Volume. 5, No. 10, (Oct. 2010), 56-64 